\title{
EMBALAGENS SUSTENTÁVEIS: $O$ ESTADO DA ARTE DA PRODUÇÃO DE TESES E DISSERTAÇÕES NOS CURSOS DE PÓS- GRADUAÇÃO EM DESIGN
}

Sustainable packaging: the state of the art of the production of theses and dissertations in post-graduation courses in Design

SASTRE, Ricardo M.; Mestre em Design; Programa de pós graduação em engenharia de produção UFRGS

ricsastre@gmail.com

DE PAULA, Istefani C; Doutora em Engenharia de produção; Programa de pós graduação em engenharia de produção - UFRGS

istefani@producao.ufrgs.br

ECHEVESTE, Márcia E.S.; Doutora em Engenharia de Produção; Programa de pós graduação em engenharia de produção - UFRGS

echeveste@producao.ufrgs.br

FERREIRA, Fernando; Bacharel em Design visual; Universidade Federal do Rio Grande do Sul UFRGS

ferreira-design@hotmail.com

\section{Resumo}

O presente estudo busca estabelecer um "Estado da arte" sobre a temática da embalagem a partir dos cursos recomendados pela CAPES no período de 1994 (primeira incidência) até 2017. O principal objetivo é mapear e discutir a produção acadêmica sobre os aspectos de sustentabilidade aplicados na embalagem. A problematização da pesquisa propõe uma discussão sobre a incidência e o que está sendo abordado sobre sustentabilidade nos trabalhos que possuem a embalagem como objeto de investigação. Esta pesquisa constitui-se como qualitativa, descritiva e interpretativa, com a utilização da técnica da pesquisa bibliográfica. Os resultados apresentaram um corpus de 2041 teses/dissertações analisadas onde foram extraídos 45 trabalhos com a temática da embalagem, dentre eles 12 abordando aspectos relacionados a sustentabilidade. Conclui-se que a pesquisa sobre embalagem nos programas de pós-graduação Stricto Sensu em Design ainda é insipiente, a maioria delas enfatiza a proposição de diretrizes ou métodos projetuais sustentáveis. O reaproveitamento de materiais também é um tema recorrente.

Palavras Chave: Embalagem; sustentabilidade; estado da arte. 


\section{Abstract}

This study seeks to establish a "state of the art" on the issue of packaging from the recommended courses by CAPES in the 1994 (first incidence) until 2017. The main objective is to discuss the academic research on aspects of sustainability applied to the packaging. The research problematization proposes a discussion about the incidence and what is being approached about sustainability in the works that have the packaging as object of investigation. This research is qualitative, descriptive and interpretive, using the technique of bibliographic research. The results presented a corpus of 2041 theses / dissertations analyzed in which 45 papers were extracted on the packaging theme, among them 12 addressing with aspects related to sustainability. It is concluded that research on packaging in the Stricto Sensu programs in Design is still insipient, most of them are concerned with defining guidelines or sustainable design methods. The reuse of materials is also a recurring theme.

Keywords: first keyword; second keyword; third and last keyword.

\section{Introdução}

Embalagens são invólucros, recipientes ou qualquer forma de acondicionamento removível ou não, destinados a cobrir, empacotar, envasar, proteger, manter os produtos ou facilitar a sua comercialização. A embalagem que se encontra em supermercados e lojas é o resultado da ação de um sistema complexo e multidisciplinar, resultante da atuação de diversos especialistas que desenvolvem atividades complementares. As embalagens estão presentes na sociedade desde o dia em que se descobriu a necessidade de proteger, conter e transportar mercadorias. Inicialmente, o homem começou a lançar mão das folhas de plantas, do couro e da bexiga de animais como matéria-prima de embalagem. Após, adotou novas tecnologias, como a cerâmica, vidro, tecido, madeira, papel, aço e plásticos (PP, PET, PE, dentre outros). Gurgel, (2007); Mestriner (2007); Cavalcanti (2006).

A partir dos grandes centros comerciais, que inicialmente tinham formato de feiras, geralmente, em uma região mais central, iniciou-se a era da produção e industrialização. Para organizar o mercado e tornar acessíveis essas mercadorias para os consumidores, surgem as lojas de departamentos. Com o desenvolvimento do mercado consumidor, as embalagens foram agregando importância e as funções primárias foram ampliadas em consequência do autosserviço. Segundo Cavalcanti, (2006) qualidades antigas, como a resistência ao transporte e à umidade, continuam essenciais, mas obrigatoriamente suplementadas por outras também importantes, como a identificação do fabricante do produto embalado e o poder de sedução exercido sobre os compradores. O que era um simples envoltório anônimo se transformou em um instrumento de propaganda e marketing.

Considera-se que a embalagem passa por constantes melhorias nos processos produtivos e no aperfeiçoamento de novas matérias-primas obtidas através da mistura de materiais e principalmente pelo seu design. É importante para o profissional responsável pelo desenvolvimento de embalagens (designer), levar em considerações os aspectos de sustentabilidade em seus projetos. Segundo Peltier (2009) as embalagens estão inseridas em um ciclo de vida e o seu processo de desenvolvimento deve considerar a integridade do produto, a 
satisfação dos consumidores e o meio ambiente.

A sustentabilidade ambiental refere-se às condições sistêmicas a partir das quais as atividades humanas, em escala mundial ou em escala local, não perturbem os ciclos naturais, além dos limites de resiliência (capacidade de tolerar uma atividade que o perturba sem perder irreversivelmente seu equilíbrio) dos ecossistemas nos quais são baseados e, ao mesmo tempo, não empobreçam o capital natural que será herdado pelas gerações futuras Manzini, (2008). A vida nas grandes metrópoles na atualidade não seria possível sem a utilização intensiva de embalagens para prover o abastecimento e o consumo de seus milhões de habitantes. Em contrapartida, ela é um importante componente do lixo produzido no planeta. Segundo Mestriner (2002) o principal componente deste lixo são os resíduos orgânicos, mas a embalagem aparece como o item de maior visibilidade, pois tem forma definida e marcas de produtos agregados a ela, ao contrário do lixo orgânico que é disforme e não apresenta marcas.

Para Peltier, (2009) a reeducação e minimização dos reflexos causados pelo descarte de embalagens, apoiam-se em uma receita da concepção sustentável baseada em três pilares: reduzir, reutilizar e reciclar. Deve-se aplicar este conceito em cada uma das etapas do ciclo de vida da embalagem, que vai desde a extração das matérias-primas, passando pela venda dos produtos e finalizando na triagem e reciclagem dos resíduos.

Diante deste cenário a embalagem torna-se relevante no contexto ambiental e a as pesquisas acadêmicas cumprem um importante papel no desenvolvimento de pesquisas e na promoção da sustentabilidade, especificamente na área do design, objeto do presente estudo que tem por objetivo mapear e discutir a produção acadêmica sobre os aspectos de sustentabilidade aplicados na embalagem. Dessa maneira, busca-se responder a seguinte questão de pesquisa: qual a incidência e o que está sendo abordado sobre sustentabilidade nos trabalhos (dissertações e teses) que possuem a embalagem como objeto de investigação?

Procurando responder esta questão, o trabalho estrutura-se da seguinte forma: após a introdução, na seção 2, apresenta-se os procedimentos metodológicos, bem como a estrutura adotada para a coleta de dados. Na seção 3, resultados e discussão, serão analisados e discutidos os dados coletados na etapa anterior. Por fim, as considerações finais e referencias.

Como contribuição teórica busca-se através do estado da arte explicitar as pesquisas nos cursos de pós-graduação em Design sobre a temática da embalagem com foco na sustentabilidade e também possíveis lacunas de pesquisa. Como contribuição prática, no final da sessão resultados e discussões, foram sugeridas recomendações sobre como reduzir, reutilizar e reciclar embalagens.

\section{Procedimentos metodológicos}

Esta pesquisa constitui-se como qualitativa, descritiva e interpretativa, com a utilização da técnica de pesquisa bibliográfica que, segundo Gil, (2010) é elaborada com base em material já publicado, incluindo tradicionalmente material impresso, neste caso teses e dissertações. Desenvolveu-se aqui o "Estado da Arte", em que se buscou mapear e analisar as pesquisas provenientes de programas de stricto sensu em Design no Brasil efetuadas em relação a temática da embalagem. Segundo Ferreira, (2002) as pesquisas denominadas estado da arte são de caráter bibliográfico e possuem em comum o desafio de mapear e discutir a produção acadêmica em 
diferentes campos do conhecimento.

O procedimento ocorreu a partir de quatro etapas: i) identificação dos programas de stricto sensu em design ou desenho industrial no Brasil recomendados pela CAPES; ii) obtenção dos resumos das teses e dissertações defendidas em cada um desses programas; iii) leitura e seleção dos trabalhos sobre a temática de investigação e, iv) categorização e análise dos dados inventariados.

O corpus selecionado para o estudo totalizou 2041 teses/dissertações defendidas entre o período de 1994 a 2017, provenientes de 23 cursos de pós-graduação em Design recomendados pela CAPES. As instituições CESAR/AM, USP/SP, UFAM/AM e UFRJ/RJ ainda não possuem publicações por estarem atuando há menos de dois anos, (tabela 1). Os cursos de pós-graduação em Design que não estão relacionados na lista oficial da CAPES foram desconsiderados. Como exemplo, cita-se o mestrado em Design da Universidade Federal de Santa Maria, que se encontra em processo de avaliação.

Tabela 1 - Número de trabalhos por instituição de ensino e sobre embalagem

\begin{tabular}{|c|c|c|c|c|c|}
\hline № & Instituição & Estado & Período & Total de trabalhos & Sobre embalagem \\
\hline 1 & CESAR & AM & 2016 a 2017 & 0 & 0 \\
\hline 2 & CESAR & $\mathrm{PE}$ & 2014 a 2017 & 5 & 0 \\
\hline 3 & UNIRITTER & $\mathrm{RS}$ & 2011 a 2017 & 71 & 3 \\
\hline 4 & UNIFATEA & SP & 2015 a 2017 & 11 & 1 \\
\hline 5 & $\mathrm{PUC} / \mathrm{RIO}$ & RJ & 1994 A 2012 & 456 & 9 \\
\hline 6 & UAM & $\mathrm{SP}$ & 2008 a 2017 & 141 & 2 \\
\hline 7 & UNIVILLE & $\mathrm{SC}$ & 2013 a 2017 & 35 & 2 \\
\hline 8 & UNB & DF & 2013 a 2017 & 22 & 0 \\
\hline 9 & USP & $\mathrm{SP}$ & 2017 & 0 & 0 \\
\hline 10 & UEMG & MG & 2009 a 2017 & 66 & 1 \\
\hline 11 & UDESC & $\mathrm{SC}$ & 2013 a 2017 & 39 & 0 \\
\hline 12 & UERJ & RJ & 2007 a 2017 & 90 & 1 \\
\hline 13 & UNISINOS & $\mathrm{RS}$ & 2009 a 2017 & 136 & 4 \\
\hline 14 & UNESP & $\mathrm{SP}$ & 1994 a 2017 & 239 & 9 \\
\hline 15 & UFCG & PB & 2014 a 2017 & 6 & 0 \\
\hline 16 & UFPE & $\mathrm{PE}$ & 2005 a 2017 & 174 & 1 \\
\hline 17 & UFSC & $\mathrm{SC}$ & 2008 a 2016 & 126 & 1 \\
\hline 18 & UFAM & AM & 2017 & 0 & 0 \\
\hline 19 & UFMA & MA & 2012 a 2017 & 31 & 1 \\
\hline 20 & UFPR & PR & 2005 a 2017 & 133 & 4 \\
\hline 21 & UFRJ & RJ & 2016 a 2017 & 0 & 0 \\
\hline 22 & UFRN & $\mathrm{RN}$ & 2013 a 2017 & 35 & 1 \\
\hline \multirow[t]{2}{*}{23} & UFRGS & $\mathrm{RS}$ & 2009 a 2017 & 225 & 5 \\
\hline & & & TOTAIS & 2041 & 45 \\
\hline
\end{tabular}

Fonte: os autores

As dificuldades na coleta de dados se deram pela falta de padrão de busca entre as universidades, pois, algumas possuem uma sessão com todos os trabalhos publicados nas páginas dos programas de pós-graduação e outras se utilizam dos repositórios das bibliotecas da instituição. Algumas bibliotecas possuem um banco de teses e dissertações, podendo utilizar filtros específicos separados pelos programas de pós-graduação. Em outros casos, a busca foi executada através de palavras chave, filtrando apenas as dissertações e teses da instituição de origem. Por constatar que em algumas instituições há uma divergência no número de trabalhos 
publicados, entre as páginas do programa de pós-graduação com as bibliotecas, foi feita a pesquisa nas duas formas em todas as instituições pesquisadas, para a obtenção dos dados da forma mais completa possível. Foi escolhida, como base, a plataforma que apresentou o maior número de trabalhos. A universidade de Santa Catarina - UFSC, disponibilizou em suas plataformas as teses/dissertações somente até o ano de 2016. O processo de busca das teses/dissertações e a leitura dos resumos e seleção dos trabalhos sobre a temática da embalagem ocorreu aos pares para evitar alguma divergência de quantidade e/ou análise.

Primeiramente procedeu-se uma leitura preliminar de todos os títulos dos trabalhos em cada um dos repositórios dos cursos recomendados pela CAPES. Aqueles que não tinham qualquer relação com a embalagem foram eliminados. Os trabalhos que continham a embalagem como tema e/ou pudessem conter de forma indireta em seu título, foram separados para leitura completa dos resumos. Em alguns casos foi necessário fazer uma leitura estendida em outras sessões para averiguar se o mesmo abordava a temática da embalagem de forma indireta. Todas as teses/dissertações de interesse foram baixadas e salvas em pastas, separados pela instituição para posterior análise.

Somaram-se 45 teses/dissertações sobre a temática da embalagem, isto é, aproximadamente $2 \%$ do montante. Assim, estes foram os trabalhos considerados neste estado da arte para uma categorização e análise, ao qual serão apresentados a seguir.

\section{Resultados e discussão}

Considerando 45 trabalhos selecionados para leitura e discussão do panorama desta temática nos cursos de pós graduação em Design no Brasil, sendo 03 teses e 42 dissertações, os quais efetivamente tratam do tema relacionado a embalagem, foi possível em um primeiro momento tecer uma análise acerca do volume de publicações, do seu conteúdo e posteriormente sobre os temas abordados ao longo dos anos.

Primeiramente observou-se a presença da temática da embalagem nos cursos de pós graduação. A UNESP divide a liderança com o maior número de trabalhos publicados sobre embalagem, totalizando 09 trabalhos, 01 tese e 08 dissertações. A PUC/RIO também possui 09 publicações, sendo 01 tese e 08 dissertações. A UFRGS é a terceira com 05 dissertações, seguida pela UFPR com 01 tese e 03 dissertações e a UNISINOS com 04 dissertações. A UNIRITTER possui 03 dissertações e a UAM e UNIVILLE 02 dissertações cada. As demais instituições que possuem publicações somam 01 dissertação cada, a UNIFATEA, UEMG, UERJ, UFPE, UFSC, UFMA e UFRN.

Na figura 1 apresenta-se um gráfico com o número de publicações relativos a temática da embalagem separados pelo ano de publicação. 
Figura 1 - Número de trabalhos por data de publicação

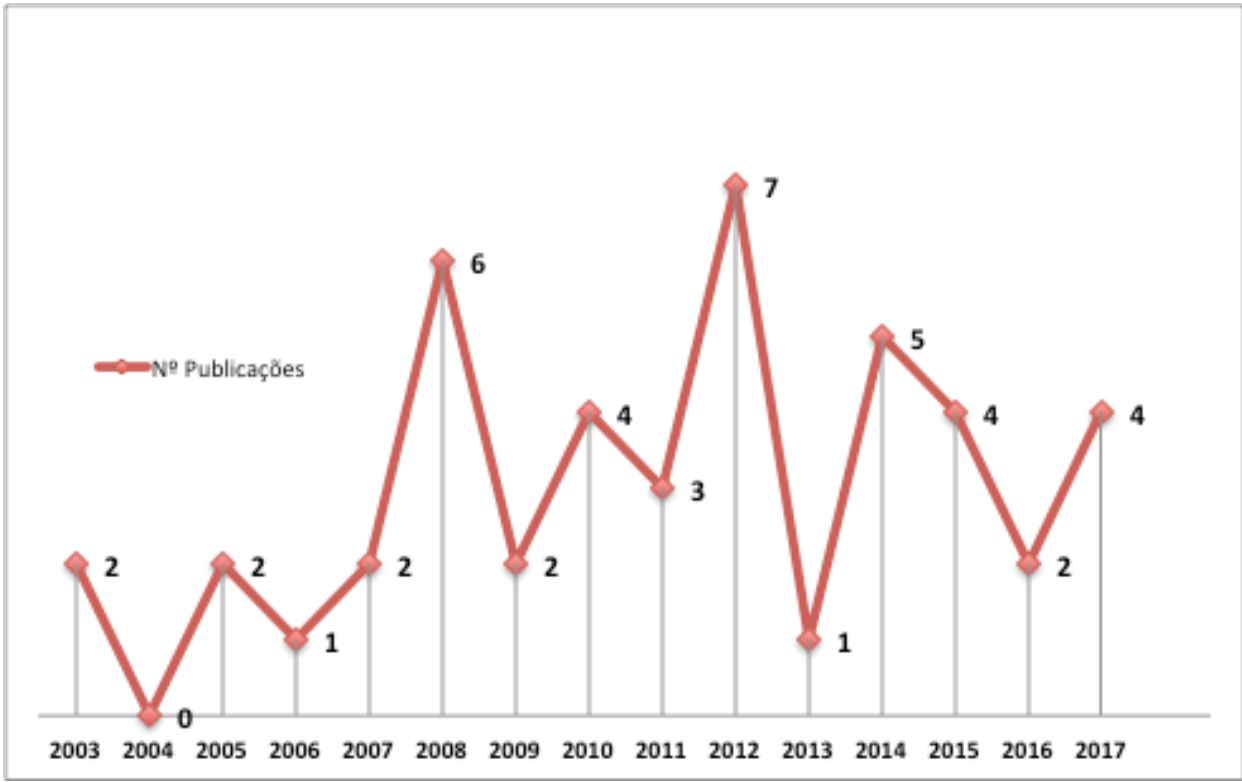

Fonte: os autores

Percebe-se que ao analisar o gráfico, os primeiros trabalhos sobre a temática da embalagem ocorreram somente no ano de 2003, ou seja, quase 10 anos após o surgimento dos primeiros cursos de pós graduação em Design no Brasil (UNESP/SP e PUC/RIO). O ano de 2012 foi o mais expressivo em volume de publicações com 07 trabalhos, seguido pelo ano de 2008 com 06 trabalhos, 2014 com 05 trabalhos e 2010, 2015 e 2017 com 04 trabalhos cada. Os demais anos mantiveram entre 01 ou 02 trabalhos publicados.

Buscando alcançar o objetivo de mapear e discutir a produção acadêmica sobre os aspectos de sustentabilidade aplicados na embalagem, a partir da observação das palavras-chave contidas nas teses/dissertações foi possível identificar quais eram as mais recorrentes, (figura 2).

Figura 2 - Nuvem de todas as palavras-chave extraídas das teses/dissertações

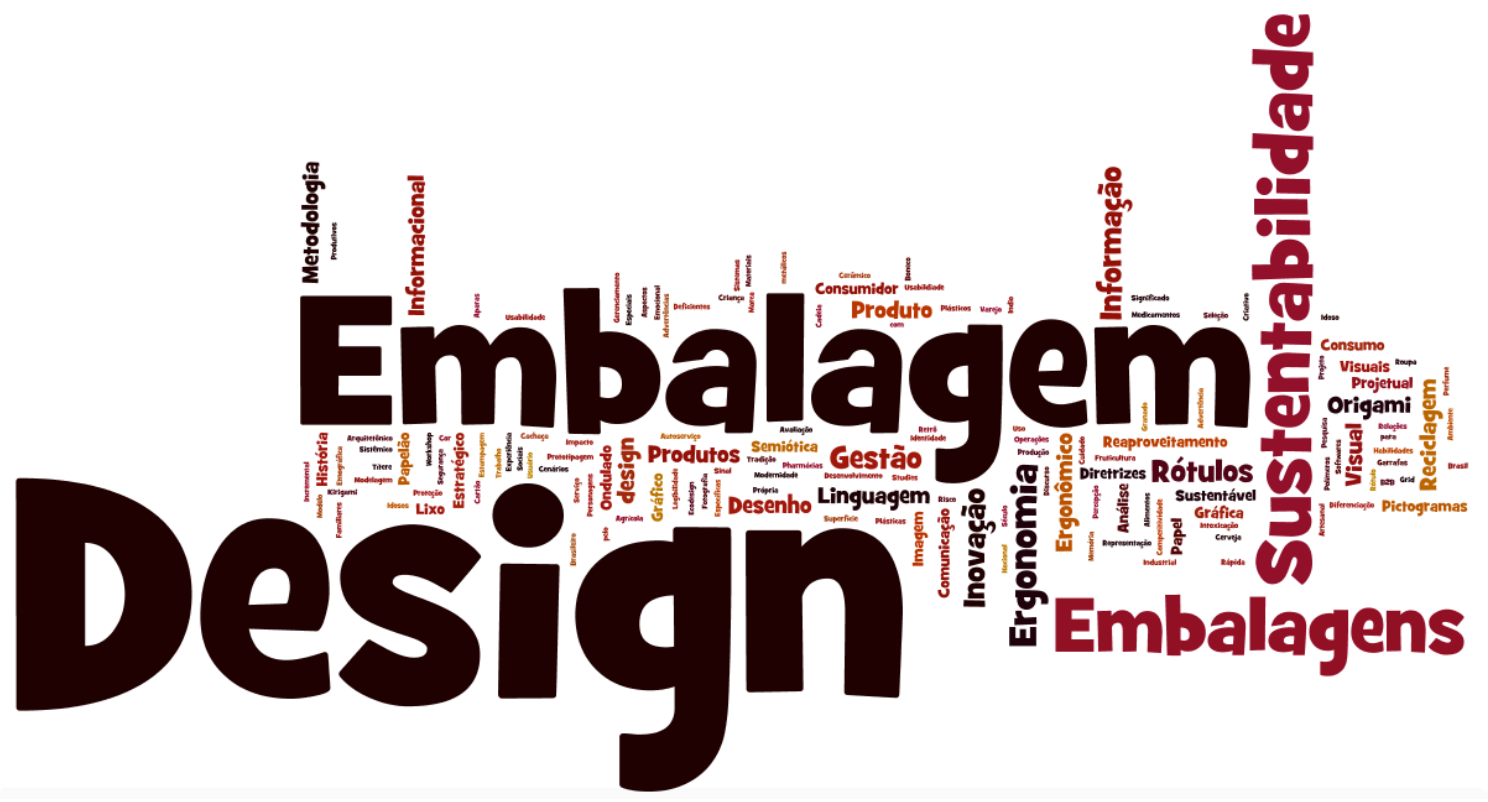

Fonte: os autores 
Foram coletadas ao todo 198 palavras-chave, aquelas que estão em destaque na nuvem da (figura 2), foram as mais recorrentes. Em primeiro lugar a palavra Design citada 41 vezes. Em segundo lugar as palavras embalagem e embalagens com 25 citações e em terceiro lugar a palavra sustentabilidade com 10 citações. Na sequência procurou-se agrupadas as palavras-chave que tivessem relação com o tema "sustentabilidade", são elas: aparas de papel; aspectos sociais; design sustentável; ecodesign; impacto ambiental; lixo; meio ambiente; reaproveitamento; reaproveitamento criativo e reciclagem.

Além da seleção de palavras-chave, foram feitas as leituras dos títulos e resumos dos 45 trabalhos sobre embalagem. Segundo Ferreira, (2002) os resumos cumprem a finalidade que Ihes está prevista em catálogos produzidos na esfera acadêmica, ou seja, informar o leitor de maneira rápida, sucinta e objetiva sobre o trabalho do qual se origina. A partir deste cruzamento de dados analisados, (título, resumo e palavras-chave), foi possível extrair os artigos que continham a temática da sustentabilidade na embalagem, foco principal deste trabalho. Dos 45 trabalhos analisados, 12 tratam da temática sustentabilidade em 05 universidades. A PUC/RIO possui 04 dissertações; na UFPR 01 tese e 02 dissertações; na UFRGS 02 dissertações; na UNISINOS 02 dissertações e a UNIRITTER 01 dissertação.

Verificou-se que as linhas de pesquisa dos cursos analisados estão alinhadas à temática investigada. A seguir descrevem-se os 12 trabalhos selecionados por instituição de origem, linha de pesquisa, autor, data e título do trabalho.

A Pontifícia Universidade Católica do Rio de Janeiro (PUC/RIO) possui 04 dissertações sobre a temática embalagem e sustentabilidade. Na linha de pesquisa tecnologia, educação e sociedade, o trabalho de Aline Rodrigues Botelho, de 2012, denominado Embalagens e produtos para cuidados com as roupas: uma análise da percepção ecológica no discurso dos consumidores, tem como foco principal investigar de que maneira os consumidores avaliam os produtos disponíveis no mercado e quais os critérios utilizam para efetuar a compra; o estudo limita-se apenas em produtos para cuidado com as roupas. Esta análise tem enfoque na sustentabilidade, e o nicho de consumidores selecionados para a pesquisa tinha alguma identificação relacionada ao meio ambiente.

O trabalho de Eduardo de Andrade Oliveira, de 2007, denominado PUPPET bonecos de PET e outros materiais descartados considera o conhecimento sobre o material como um dos principais requisitos para a realização de um produto e propõe uma investigação do PET na construção de bonecos. Apresenta como o designer pode se apropriar deste material, contribuindo na concepção de personagens/bonecos. Em segundo plano, apresenta o teatro de títeres como uma mídia que instaura significados próprios que contribuem para a apropriação do conhecimento.

Na linha de pesquisa Ergonomia e usabilidade e interação humano-computador, o trabalho de Jordan de Castiglione Neville Larica, de 2005, denominado Intervenção do design na recuperação de tampas de garrafas, analisa a intervenção do design na recuperação de tampas de garrafa e outras pequenas peças plásticas. $O$ design pode atuar como agente transformador que intervém para redirecionar o descarte, estimular a devolução e facilitar a recuperação de embalagens plásticas. Um cenário de insustentabilidade que pode ser mudado com a aplicação do "Ecodesign", que concorre para a minimização da geração de resíduos e da exploração de recursos 
naturais, promovendo a recuperação do material plástico a ser reciclado para aplicações posteriores.

O trabalho de Augusto Seibel Machado, de 2008, denominado A questão das embalagens e sua relação com a sustentabilidade busca compreender as principais relações estabelecidas com o sistema de embalagens do cotidiano, o modo como se consome, utiliza e descarta. Foram analisados diversos aspectos dos sistemas de embalagens, sua importância para o comércio, para o atual estilo de vida da sociedade, os variados impactos ambientais, os ciclos de vida que apresentam sua participação na problemática do lixo e o desperdício de recursos por ele representado, bem como o estudo de diferentes ciclos de vida das embalagens. Foi apresentado um estudo de caso específico em embalagens utilizadas em tomates in natura.

A Universidade Federal do Paraná (UFPR) possui 01 tese e 02 dissertações sobre embalagem e sustentabilidade. A linha de pesquisa é design, sistemas de produção e utilização. $O$ trabalho de Cláudio Pereira de Sampaio, de 2008, denominado Diretrizes para o design de embalagens em papelão ondulado movimentadas entre empresas com base no sistema produto-serviço, trata do papel do design como atividade que favoreça a sustentabilidade ambiental de embalagens em papelão ondulado utilizadas para o transporte entre empresas (B2B - business-to-business). Propõe o uso de diretrizes de projeto, baseadas em sistemas produtoserviço (PSS). Para tanto, se utilizou como estratégia de pesquisa um estudo de caso em uma indústria automotiva da região metropolitana de Curitiba

O trabalho de Jair Mello Jarek, de 2014, denominado Design e inovação no aproveitamento sustentável de resíduos em empresas de embalagens de papelão teve o objetivo de adicionar maior valor agregado às aparas de caixas de papelāo ondulado ao reaproveitá-las de forma inovadora como preenchimento e calço em embalagens de transporte. 0 estudo buscou o uso de uma tecnologia de baixa complexidade baseada em compósitos de fibras e papel. O trabalho proposto, demonstrou os resultados e conceitos procurados: diminuir o custo e a movimentação da reciclagem ao manter o processamento dos resíduos dentro da empresa; aumentar o valor agregado dos resíduos transformando-os em um produto comercial; facilitar a armazenagem sendo um produto empilhável; ter baixo peso com boa resistência para proteger o produto transportado.

A tese de Dulce de Meira Albach, de 2017, denominado Design para sustentabilidade em cenários futuros no setor de embalagens de alimentos em autosserviço afirma que o Design para Sustentabilidade propõe o alcance de uma descontinuidade dos padrões atuais de produção e consumo, considerada como essencial para se atingir transformações com resultados mais promissores. Exploraram-se nesta pesquisa dois setores de importante representatividade: a indústria de embalagens e a de alimentos, e interpretadas no ambiente supermercado (autosserviço) enquanto local de grande concentração de ambas. Esta tese propõe, desta forma, refletir sobre como definir estratégias que propiciem parâmetros para decisões orientadas ao Design para Sustentabilidade no setor de embalagens de alimentos em autosserviço.

A Universidade Federal do Rio Grande do Sul (UFRGS) possui 02 dissertações sobre a temática embalagem e sustentabilidade. Na linha de pesquisa produtos industriais, gráficos e sistemas visuais o trabalho de André Noronha Furtado de Mendonça, de 2010, denominado Design de advertência: contribuições para a reciclagem no Brasil com foco na rotulagem de 
embalagens, contribui para o aperfeiçoamento da reciclagem no Brasil, observando qual é o contexto atual da reciclagem, investigando o seu histórico, os conceitos envolvidos, os dados mais atuais, quais são os órgãos governamentais e não governamentais que se dedicam a este tema, em que nível se encontram, e sobre o que tratam as normas técnicas e a legislação brasileira. Foi observado como se processa a reciclagem em termos regionais, com recorte na cidade de Porto Alegre. A partir destas observações iniciais, foi necessário compreender quais são os agentes que se relacionam com o produto ao longo de seu ciclo de vida e como ocorrem estas relações. Estas análises permitiram compreender melhor o papel do Estado, da iniciativa privada, da sociedade e do indivíduo na construção de um mundo sustentável ou de uma cultura pró-sustentabilidade; viabilizou também uma definição de quais contribuições podem ser apresentadas para que seja possível aperfeiçoar a reciclagem no Brasil.

Na linha de pesquisa projeto de artefatos, o trabalho de Priscila Zavadil Pereira, de 2012, denominado Proposição de metodologia para o design de embalagem orientada à sustentabilidade, propõe um método para o design de embalagens que tenha como premissa a sustentabilidade ambiental, social e econômica, com foco em produtos locais. Para tanto, realizouse uma análise comparativa dos métodos de design de embalagem quanto aos procedimentos adotados e as formas de inserção da sustentabilidade em cada metodologia. Assim, foi possível sistematizar um método para aplicação na fase de coleta de dados, realizada a partir da abordagem qualitativa e da observação participante. O método foi aplicado em um projeto de extensão universitária e no ensino projetual em cursos de graduação em design. A análise dos dados permitiu encontrar parâmetros que orientaram o desenvolvimento do método final proposto, com base nos principais métodos de design de embalagem, em abordagens sistêmicas e em métodos orientados à sustentabilidade. $O$ trabalho é concluído com a proposição do método CICLO, composto por cinco fases: compreender, idealizar, configurar, lapidar e orientar e um conjunto de ferramentas e diretrizes que podem ser utilizadas de acordo com a necessidade do projeto de embalagem.

O Centro Universitário Ritter dos Reis (UNIRITTER) possui 1 dissertação sobre a temática embalagem e sustentabilidade. A linha de pesquisa é design, tecnologia e educação. O trabalho de Évelyn Parrilha Bisconsin, de 2012, denominado Método especialista de projeto de embalagem com foco no correto descarte e posterior reciclagem: um caso para comunicar o correto descarte do consumidor, considera a prática profissional de design gráfico através de parâmetros sustentáveis, analisando o impacto ambiental do descarte de embalagem e da comunicação visual sobre o correto descarte e reciclagem. O trabalho investiga a relação do projetista da embalagem com a problemática ambiental e propõe uma metodologia com esse foco, validando através de uma pesquisa ação, aplicada a uma embalagem de cuca orgânica.

A Universidade do Vale do Rio dos Sinos (UNISINOS) possui 2 dissertações sobre a temática embalagem e sustentabilidade. A linha de pesquisa é processo de projetação para inovação. 0 trabalho de Lidiane Camiloti, de 2011, denominado Design estratégico e inovação para o desenvolvimento de embalagens ecossustentáveis afirma que um dos principais objetivos das empresas da área de alimentação é desenvolver e introduzir produtos com embalagens inovadoras no mercado, num período de tempo reduzido. O estudo investiga quais são as metodologias ou processos utilizados para o desenvolvimento de embalagens pelas empresas/escritórios de design do extremo oeste de Santa Catarina e busca contribuir, com base 
no comparativo, uma proposta de design estratégico para o setor, trazendo como questão de fundo a problemática da sustentabilidade.

O trabalho de Priscila Westphal Rodrigues, de 2014, denominado 0 design estratégico na representação da sustentabilidade das embalagens Natura Ecos busca investigar como o Design Estratégico pode potencializar os efeitos de sentido a partir das percepções sobre a sustentabilidade das embalagens dos produtos da Natura Ecos. A partir dos resultados da pesquisa, apontam-se cinco diretrizes projetuais para a criação de sistemas produto-serviço para potencializar os efeitos de sentido das representações gráficas que remetem à sustentabilidade: i) criando a sustentabilidade; ii) gerando as estratégias de sustentabilidade; iii) reconhecendo as informações; iv) reconhecendo os materiais e, v) repensando as formas do design.

Estes trabalhos foram publicados entre os anos de 2005 a 2017, sendo o ano de 2012 o de maior número de publicações, com 3 dissertações. A única tese, da UFPR, do montante dos 12 trabalhos descritos foi publicada no ano de 2017. Os trabalhos analisados foram agrupados em categorias. O critério de categorização adotado foi do tipo lexical, foram agrupadas em categorias segundo os sentidos próximos. A classificação dos trabalhos em categorias impôs uma investigação do que cada uma possuía em comum, caracterizando-se por ser um processo do tipo estruturalista. Ressalta-se que o pesquisador está consciente que os agrupamentos estabelecidos estavam relacionados com a realidade oferecida. Neste processo, identificaram-se os seguintes agrupamentos: i) comportamento do consumidor sobre a sustentabilidade; ii) reaproveitamento de materiais; iii) diretrizes e métodos do projeto e, iv) diretrizes de sustentabilidade. Os agrupamentos que possuem maior incidência são, respectivamente, diretrizes e métodos do projeto , com 07 trabalhos; Reaproveitamento de materiais com 03 trabalhos e comportamento do consumidor sobre a sustentabilidade e diretrizes de sustentabilidade com 01 trabalho cada. A (tabela 3) apresenta os trabalhos agrupados.

\begin{tabular}{|c|c|}
\hline Categorias & Teses/dissertações \\
\hline $\begin{array}{l}\text { 1. Comportamento do } \\
\text { consumidor sobre a } \\
\text { sustentabilidade }\end{array}$ & $\begin{array}{l}\text { - Embalagens e produtos para cuidados com as roupas: uma análise da } \\
\text { percepção ecológica no discurso dos consumidores }\end{array}$ \\
\hline $\begin{array}{l}\text { 2. Reaproveitamento } \\
\text { de materiais }\end{array}$ & $\begin{array}{l}\text { - PUPPET bonecos de PET e outros materiais descartados; } \\
\text { - Intervenção do design na recuperação de tampas de garrafas; } \\
\text { - Design e inovação no aproveitamento sustentável de resíduos em } \\
\text { empresas de embalagens de papelão. }\end{array}$ \\
\hline $\begin{array}{l}\text { Diretrizes e } \\
\text { métodos do projeto }\end{array}$ & $\begin{array}{l}\text { - A questão das embalagens e sua relação com a sustentabilidade; } \\
\text { - Diretrizes para o design de embalagens em papelão ondulado } \\
\text { movimentadas entre empresas com base no sistema produto-serviço } \\
\text { - Design para sustentabilidade em cenários futuros no setor de } \\
\text { embalagens de alimentos em autosserviço; } \\
\text { - Proposição de metodologia para o design de embalagem orientada à } \\
\text { sustentabilidade; } \\
\text { - Método especialista de projeto de embalagem com foco no correto } \\
\text { descarte e posterior reciclagem: um caso para comunicar o correto } \\
\text { descarte do consumidor }\end{array}$ \\
\hline
\end{tabular}




\begin{tabular}{l|l}
\hline & $\begin{array}{l}\text { - Design estratégico e inovação para o desenvolvimento de embalagens } \\
\text { ecossustentáveis; } \\
- \text { O design estratégico na representação da sustentabilidade das } \\
\text { embalagens Natura Ecos. }\end{array}$ \\
\hline $\begin{array}{l}\text { 4. Diretrizes de } \\
\text { sustentabilidade }\end{array}$ & $\begin{array}{l}\text { - Design de advertência: contribuições para a reciclagem no Brasil com } \\
\text { foco na rotulagem de embalagens. }\end{array}$ \\
\hline
\end{tabular}

Conclui-se que a pesquisa sobre embalagem nos programas de pós-graduação Stricto Sensu em Design pode ser melhor explorada, possui atualmente aproximadamente $2 \%$ do total de teses/dissertações, o que pode ser considerado baixo. Dentre os 45 trabalhos sobre embalagem, apenas 12 abordam aspectos relacionados a sustentabilidade, ou seja, aproximadamente $30 \%$. A maioria deles enfatiza a proposição de diretrizes ou métodos projetuais sustentáveis, readaptando um processo produtivo existente ou propondo a criação de embalagens sustentáveis desde o inicio do projeto, observando cada etapa do seu ciclo de vida. O reaproveitamento de materiais também é uma preocupação aparente, no sentido de aumentar a vida útil dos produtos e/ou diminuir a extração de matéria-prima da natureza. De forma moderada através de uma dissertação estuda-se o comportamento do consumidor (consumo consciente) sobre a sustentabilidade e também levanta-se questões sobre as diretrizes de sustentabilidades aplicáveis em projetos de embalagem.

Recomenda-se como ações para reduzir a quantidade de recursos naturais necessários na fabricação de embalagens, à redução da quantidade de energia utilizada, à redução da poluição da atmosfera, à redução do volume de resíduos e à redução dos percursos no transporte de mercadorias. Busque Reduzir a quantidade de matérias-primas necessárias à fabricação de embalagens através da otimização de espaços no papel em projetos estruturais ou através da redução do peso (gramatura do papel), reduzindo-se a quantidade de aparas (sobras de papel). Observe embalagens compactas, que reduzam o volume e que otimize espaços no transporte e na armazenagem, proporcionando redução de energia e poluição do ar. Pense em não utilizar subembalagens (berços) ou que possam ser substituídas por projetos estruturais econômicos, no que diz respeito ao uso do papel. Pondere o uso de papéis branqueados com cloro e diminua o uso de tintas e vernizes.

As ações sugeridas sobre a sua reutilização podem ser através de embalagens (retornáveis) para o mesmo uso depois de uma limpeza; ao desenvolvimento de embalagens menores que sirvam como refis e à reutilização da embalagem para outros fins. Observe as embalagens que possam ser utilizadas diversas vezes pelo mesmo produto após uma rápida limpeza e que contenham um sistema de coleta em pontos de vendas, que oriente e incentive os consumidores para esta finalidade. Verifique embalagens que sirvam como refis, mas que sejam mais econômicas e utilize menos materiais do que as embalagens originais. Pense na reutilização da embalagem após o uso do produto, proporcionando o prolongamento em seu tempo de vida e pode servir como utilitário. Exemplos: cofres de papel, porta objetos, acessórios decorativos, artesanato, colecionáveis, dentre outros.

Busque ações para o correto descarte da embalagem, evitando que elas se tornem resíduos terminais. As medidas para a otimização da reciclagem da embalagem podem ocorrer através da correta identificação dos materiais impressos na embalagem; da facilitação da 
separação dos diferentes materiais; do incentivo à compactação de embalagens volumosas, que reduzem o custo no transporte, e a opção por matérias primas $100 \%$ recicláveis. Busque espaços que facilitem a comunicação sobre os tipos de materiais que contém a embalagem e o desenvolvimento de selos e ícones de identificação sobre a correta reciclagem. Pense em projetos estruturais que contemplem a compactação da embalagem e que possam ser desmontáveis, facilitando o transporte para o encaminhamento da reciclagem. Pondere o uso de materiais reciclados ou recicláveis na concepção do projeto da embalagem; não utilize a mistura de matérias-primas; opte por materiais que possam ser facilmente separados; e realize pesquisas sobre matérias-primas sustentáveis disponíveis no mercado.

\section{Considerações finais}

Este estudo permitiu traçar um parâmetro brasileiro de relevância acadêmica sobre a temática da embalagem e sustentabilidade. Foram analisados teses e dissertações ao longo de vinte e três anos, mostrando que no Brasil a evolução do tema é lenta e não gradual. Devido a importância que a embalagem se apresenta como geradora de lixo no planeta e do importante papel que o Designer ocupa como projetista, este assunto deveria ser mais explorado no ambiente acadêmico.

O amadurecimento da temática da sustentabilidade aplicada na embalagem pode evoluir no sentido de proposição de projetos que objetivam reduzir o consumo de recursos naturais, na promoção da conscientização dos consumidores através de uma linguagem visual mais clara sobre os materiais contidos na embalagem, bem como a instrução ao correto descarte e reciclagem, na construção de dispensadores de embalagens vazias e no aumento do ciclo de vida da embalagem através da reutilização. Estes são exemplos que podem ser aplicados no mercado ou possíveis lacunas de pesquisas a serem exploradas em trabalhos futuros.

Dessa maneira, a questão de pesquisa proposta sobre qual a incidência e o que está sendo abordado sobre sustentabilidade nos trabalhos que possuem a embalagem como objeto de investigação foi respondida ao longo deste trabalho. Em constatação expõe uma lacuna importante na construção teórica sobre os aspectos de sustentabilidade nas pesquisas em design brasileira expandindo o estado da arte a partir do número total de teses/dissertações selecionando todos os trabalhos que abordem sustentabilidade de uma maneira geral e não somente na embalagem.

\section{Referências}

ALBACH, Dulce M. Design para sustentabilidade em cenários futuros no setor de embalagens de alimentos em autosserviço. 2017. Tese (Doutorado em Design) - Universidade Federal do Paraná, Paraná.

BISCONSIN, Évelyn P. Método especialista de projeto de embalagem com foco no correto descarte e posterior reciclagem: um caso para comunicar o correto descarte do consumidor. 2012. Dissertação (Mestrado em Design) - Centro Universitário Ritter dos Reis, Porto Alegre.

BOTELHO, Aline R. Embalagens e produtos para cuidados com as roupas: uma análise da percepção ecológica no discurso dos consumidores. 2012. Dissertação (Mestrado em Design) Pontifícia Universidade Católica do Rio de Janeiro, Rio de Janeiro. 
CAMILOTI, Lidiane. Design estratégico e inovação para o desenvolvimento de embalagens ecossustentáveis. 2011. Dissertação (Mestrado em Design) - Universidade do Vale do Rio dos Sinos, Porto Alegre.

CAPES. Cursos recomendados. Disponível em: < https://sucupira.capes.gov.br/sucupira/public/consultas/coleta/programa/quantitativos/quantitat ivoles.jsf ?areaAvaliacao=29\&areaConhecimento=61200000 . Acesso em: 30 jan. 2018.

CAVALCANTI, Pedro. História da embalagem no Brasil. São Paulo: Grifo Projetos Históricos e Editoriais, 2006.

FERREIRA, Norma Sandra de Almeida. As pesquisas denominadas "estado da arte". Educação e Sociedade, São Paulo, ano 23, n.79, p. 257-272, 2002.

GIL, Antonio Carlos. Como elaborar projetos de pesquisa. São Paulo: Atlas, 2010.

GURGEL, Floriano do Amaral. Administração da embalagem. São Paulo: Thomson, 2007.

JAREK, Jair M. Design e inovação no aproveitamento sustentável de resíduos em empresas de embalagens em papelão. 2014. Dissertação (Mestrado em Design) - Universidade Federal do Paraná, Paraná.

LARICA, Jordan C. N. Intervenção do design na recuperação de tampas de garrafas. 2005. Dissertação (Mestrado em Design) - Pontifícia Universidade Católica do Rio de Janeiro, Rio de Janeiro.

MACHADO, Augusto S. A questão das embalagens e sua relação com a sustentabilidade. 2008. Dissertação (Mestrado em Design) - Pontifícia Universidade Católica do Rio de Janeiro, Rio de Janeiro.

MANZINI, Ezio. O desenvolvimento de produtos sustentáveis. São Paulo: Editora da Universidade de São Paulo, 2005.

MENDONÇA, André N.F. Design de advertência: contribuições para a reciclagem no Brasil com foco na rotulagem de embalagens. 2010. Dissertação (Mestrado em Design) - Universidade Federal do Rio Grande do Sul, Porto Alegre.

MESTRINER, Fabio. Design de embalagem: curso básico. São Paulo: Pearson Makron Books, 2002.

MESTRINER, Fabio. Gestão estratégica de embalagem. São Paulo: Pearson Prentice Hall, 2007.

OLIVEIRA, Eduardo de A. PUPPET bonecos de PET e outros materiais descartados. 2007. Dissertação (Mestrado em Design) - Pontifícia Universidade Católica do Rio de Janeiro, Rio de Janeiro.

PELTIER, Fabrice. Design sustentável: caminhos virtuosos. São Paulo: Senac, 2009.

PEREIRA, Priscila Z. Proposição de metodologia para o design de embalagem orientada à sustentabilidade. 2012. Dissertação (Mestrado em Design) - Universidade Federal do Rio Grande do Sul, Porto Alegre.

RODRIGUES, Priscila W. O design estratégico na representação da sustentabilidade das embalagens Natura Ecos. 2014. Dissertação (Mestrado em Design) - Universidade do Vale do Rio dos Sinos, Porto Alegre. 


\section{Artigo Completo}

SAMPAIO, Cláudio P. Diretrizes para o design de embalagens em papelão ondulado movimentadas entre empresas com base no sistema produto-serviço. 2008. Dissertação (Mestrado em Design) - Universidade Federal do Paraná, Paraná. 